\title{
Factors Associated with the Implementation of the Nursing Process in the Public Hospitals of Lubumbashi in the Democratic Republic of Congo: A Cross-Sectional Descriptive Study
}

\author{
Ndayi Kabamba Julie1, Ilunga Kandolo Simon ${ }^{1}$, Matungulu Matungulu Charles ${ }^{1}$, \\ Kabange Umba Irène ${ }^{1}$, Abdulu Mahuridi ${ }^{1}$, Mwinkeu Kasongo Narcisse ${ }^{2}$, \\ Mundongo Tshamba Henry¹, Omanyondo Ohambe Marie Claire ${ }^{3}$, Malonga Kaj Françoise1,4 \\ ${ }^{1}$ School of Public Health, University of Lubumbashi, Lubumbashi, Democratic Republic of the Congo \\ ${ }^{2}$ Institute of Medical Techniques of Lubumbashi, Lubumbashi, Democratic Republic of the Congo \\ ${ }^{3}$ Institute of Medical Techniques of Kinshasa, Kinshasa, Democratic Republic of the Congo \\ ${ }^{4}$ Faculty of Medicine, University of Lubumbashi, Lubumbashi, Democratic Republic of the Congo \\ Email: *silungak@gmail.com
}

How to cite this paper: Julie, N.K., Simon, I.K., Charles, M.M., Irène, K.U., Mahuridi, A., Narcisse, M.K., Henry, M.T., Claire, O.O.M. and Françoise, M.K. (2017) Factors Associated with the Implementation of the Nursing Process in the Public Hospitals of Lubumbashi in the Democratic Republic of Congo: A Cross-Sectional Descriptive Study. Open Access Library Journal, 4: e4054. https://doi.org/10.4236/oalib.1104054

Received: October 23, 2017

Accepted: November 20, 2017

Published: November 23, 2017

Copyright $\odot 2017$ by authors and Open Access Library Inc.

This work is licensed under the Creative Commons Attribution International License (CC BY 4.0).

http://creativecommons.org/licenses/by/4.0/ (c) (i) Open Access

\begin{abstract}
Introduction: The nursing process is an organized method that focuses on the individual reactions of a person (or group) in order to produce a clinical judgment about the person's state of health in order to make decisions about to the care to be given [1]. Method: The qualitative study has been carried out in this work. This involves exploring the factors related to their experience and the feelings of each caregiver in order to identify possible pathways for the implementation of the nursing process in public hospitals in Lubumbashi. Results: The results showed that the factors that can favor the implementation of the nursing process according to the expression of the nurses surveyed are: updating knowledge on the nursing procedure, setting up the nursing file, availability nursing staff (sufficient staff and permanence in the workplace), motivation of nurses (salary, promotion, bonus, etc.), availability of work equipment. Conclusion: Ultimately, the main challenges remain the training, the equipment of the hospitals and the financial motivation of the nurses.
\end{abstract}

\section{Subject Areas}

Nursing

\section{Keywords}

Nursing Process, Nursing, Promoting Factors 


\section{Introduction}

The nursing process is used in clinical practice worldwide to provide patients with quality individualized care, and the absence of its application can reduce the quality of care [2].

Zaragoza Salcedo Amparo mentions among the factors that facilitated the implementation of the nursing process, the nursing process education program, with particular attention to increasing knowledge, evolution attitudes and skills development; the availability of nursing documents that facilitate the development of nurses' skills, particularly communication and problem-solving [3].

For more effective implementation of the nursing process in a hospital, Zewdu proposed the supervision of activities in order to achieve this success. In addition, the nurse should train periodically and information should be disseminated about the nursing process [4]. When the difficulties persist, Afoi, proposed the availability of nurses at all hours of operation and the availability of basic nursing care equipment for patients [5]. Beforehand, these nurses are sensitized, supervised, reinforced and even punished for those who do not respect the norms. In addition, appropriate working conditions and appropriate human resources are also assets for the successful implementation of the nursing process [6]. Kollie recommended reviewing the workload of nurses, making printed materials available, and using information technology to stimulate the use of the nursing process [7].

In R.D. Congo and especially in Lubumbashi, according to our knowledge to date, the nursing process is not implemented in public hospitals. There are no writings on the nursing process. We have set ourselves the goal of exploring the factors that can contribute to the implementation of the nursing process in Lubumbashi in order to contribute to improving the quality of care.

\section{Material and Method}

Our study was carried out in the Democratic Republic of Congo, in the province of Upper Katanga (one of the four dismembered provinces of the former province of Katanga), in the city of Lubumbashi in June 2016.

The interviews were conducted by two teachers, one from the University of Lubumbashi and another from the Lubumbashi Institute of Medical Technics. The interviews took place in various governmental hospitals chosen to conduct our study. We conducted a qualitative study. For convenience and reasoning, we selected nurses who were able to express themselves easily on the nursing process. We used the focus group with 3 questions on the place of the nursing process in the day-to-day work of nurses, the conditions for implementing the nursing process and the factors that can help to implement the nursing process. nursing process in public hospitals in Lubumbashi. Six groups of 12 nurses have been set up. Data collection was pre-tested with nurses not in this study. The focus group data were recorded and transcribed to allow their exploitation from the qualitative analysis grids. The individual data has been digitally coded for use 
on a computer. The participants in the study were predominantly female, married as single, of different religions, and all of the higher education level (Under graduates).

\section{Results}

\begin{tabular}{|c|c|c|c|}
\hline & Category & Sub-category & Verbatim \\
\hline $\begin{array}{l}\text { Theme 1: } \\
\text { The place of the nursing } \\
\text { process in professional } \\
\text { practice }\end{array}$ & $\begin{array}{l}\text { - Primordial/important place } \\
\text { - Main focus of health problem solving }\end{array}$ & & $\begin{array}{l}\text { "... it is considered as a } \\
\text { starting point for better } \\
\text { solutions for the care of the } \\
\text { sick..." }\end{array}$ \\
\hline $\begin{array}{l}\text { Theme 2: } \\
\text { Conditions for Implementing } \\
\text { the Nursing process. }\end{array}$ & $\begin{array}{l}\text { - Availability of the nurse } \\
\text { - Balance of nurse/patient ratio } \\
\text { - Capacity Building } \\
\text { - Availability of the nursing file } \\
\text { - Individualization of care }\end{array}$ & $\begin{array}{l}\text { - Permanence } \\
\text { - Sufficient time to spend } \\
\text { - Dedication } \\
\text { - Good recruitment of nurses } \\
\text { - work-friendly environment } \\
\text { - make the nurse aware of his role } \\
\text { - train the nurse on the job }\end{array}$ & $\begin{array}{l}\text { "... the nurse must first master } \\
\text { the steps and the nurse must be } \\
\text { trained, so to be remembed,..." }\end{array}$ \\
\hline $\begin{array}{l}\text { Theme 3: } \\
\text { Factors that can facilitate the } \\
\text { implementation of the } \\
\text { nursing process }\end{array}$ & $\begin{array}{l}\text { - Motivation } \\
\text { - Availability of staff } \\
\text { - Knowledge update } \\
\text { - Improvement of the working climate } \\
\text { - Implementation of the nursing file } \\
\text { - Improvement of the esteem and image } \\
\text { of the nurse } \\
\text { - Awareness }\end{array}$ & $\begin{array}{l}\text { - Sufficient salary } \\
\text { - Increase in risk premium } \\
\text { - Gratification } \\
\text { - Increase in staff } \\
\text { - Rejuvenating teams } \\
\text { - On-the-job training } \\
\text { - Capacity Building } \\
\text { - Stress reduction } \\
\text { - Facilitate interpersonal relations. } \\
\text { - Defining the actions of nurses } \\
\text { - Make the file available } \\
\text { - Correct filling of the backrest } \\
\text { - Awareness of the nurse } \\
\text { - Considerations by peers and line } \\
\text { managers }\end{array}$ & $\begin{array}{l}\text { The nurse ... especially } \\
\text { motivated whatever } \\
\text { marginalized, a little } \\
\text { discriminated, works a little too } \\
\text { much and, he receives little, so a } \\
\text { little money... he will not work } \\
\text { well ... } \\
\text {... also have training ... we all } \\
\text { consider ourselves as service } \\
\text { providers ... }\end{array}$ \\
\hline
\end{tabular}

\section{Discussion}

1) Perception of the nurses of the public hospitals of Lubumbashi on the place of the nursing process in the daily work of the nurses

Most respondents stated that the nursing process is an important part of the nurse's daily work. "The nursing process is an important part of the day-to-day work of nurses because it enables nurses to achieve effective care and improve the quality of care", "... the nursing process is an essential place ...", “... a key place...", “... a key and priority place ...". Our results are consistent with those of Aiyedun in Abuja [2], who found that $69 \%$ of nurses believe that quality nursing 
care cannot be achieved without the nursing process, and Ethiopia, where $88 \%$ of nurses said that the process of nursing helps provide quality nursing care [8].

2) Prerequisites for the implementation of the nursing process in public hospitals in Lubumbashi

a) Availability of nurses and balance of nurses/patient's ratio

Our study shows that the availability of nurses is the first condition for the implementation of the nursing process. This availability is the result of the balance ratio of nurses/ patients. Some nurses said, "There is a staffing problem. You see, for example, a nurse who is in a department with 25 patients ...", "for the nurse to be available, ... add the nursing staff", “... for the sufficiency of time to be spent on patients". In this regard, Afoi emphasized the availability of the nurse at all hours of duty [5]. Kollie recommended that health facilities review the workload of nurses to stimulate the use of the nursing process [7]. As for Mahnaz [6], human resources must be adapted. Aslakson argued that the most important barriers are the lack of time to follow the nursing process due to the excessive number of patients (84.1\%), and the submission of non-nurses to nurses [9].

\section{b) Training on nursing care}

Our results show that on-the-job training is the second condition for the nursing process to be implemented. The nurses stated that "there is also a need for retraining", "awareness must be given to what should be done and what should not be done", "nurses need to be trained, some stories that we have already forgotten...”, "There are no qualified nurses on the nursing process", “... the nurse must first master the steps of the nursing process for it must be formed, therefore remember, ...”.

In Egypt, Nigeria and Iran, authors also found the same thing and respondents wanted staff to be sensitized to the nursing process and supervised to ensure that the nursing process was actually implemented [6] [10] [11].

\section{c) Availability of the nursing file}

The nursing file is the third condition for the implementation of the nursing process. In our study, nurses needed the nursing record; because they think: “... the data, we have to put them somewhere, we analyse and there it will enable us to continue our art of care and to allow a good continuity of care ...," We need a nursing file", "The support we have, does not give us time to think and we have a sheet of two-sided sides ... You do not have space that can allow application", “... standardization of the nursing file ...”.

Kollie proposed that health facilities provide printed materials to stimulate the use of the nursing process [7].

3) Factors that can facilitate the implementation of the nursing process in public hospitals in Lubumbashi

a) Improving the esteem, image of the nurse and the social climate

In line with our results, respondents are asking for improvements in the esteem, image of the nurse and the social climate. They said, "Do not marginalize the nurse", "Do not be hindered by doctors", "Consider us too", "Awareness of 
the nurse", "Consideration by peers and hierarchical leaders" "Stress Reduction", "Facilitating Interprofessional Relationships", "A nurse may also lose skills because of the environment in which he works, ... if the environment is not conducive to quality improvement ...".

\section{b) Implementation of the nursing file.}

In our study, setting up the nursing file is one of the factors that can help to implement the nursing process. The nurses said: "If we go back to healthcare where we have to collect the data, the data we keep in our heads, we have to put it somewhere, we analyze it and it will allow us to continue our art of care and to allow a good continuity of care ....". Brou Ahonzi found that $72 \%$ of nurses in his sample were in favor of a nursing record in addition to the existing medical record already in the department [12].

\section{c) Availability of nurses.}

The availability of nursing staff is one of the conditions and a factor that can help to implement the nursing process. Almost all respondents felt that nurses needed to be available and accepted for the nursing process to be implemented in public hospitals in Lubumbashi. The following remarks were made by the nurses: "There is the staff, the staff, you see, for example, a nurse who is in a department with 25 patients," "Add the number of nurses". Kollie found that the work of nurses to stimulate the use of the nursing process [7]. In Rwanda, according to Juliana, the application of the nursing process requires in addition knowledge and skills of good working conditions, for this a nurse should not exceed at least 5 patients for a good nursing care [13].

\section{d) Updating knowledge about the nursing process}

Another factor that can contribute to the implementation of the nursing process, according to our respondents, is the updating of knowledge about the nursing process. Here is what they said:

"There are no qualified nurses on the nursing process", “... we have to be retrained so that we are up to date ...", “... we need a base, and this base there begins first through training and retraining", "Raising nurses' awareness of the nursing process", "There is also a lack of training", "It also needs recycling", "Raising awareness about what to do and what should not be done", "Nurse training", "Nurses be briefed on the nursing process so that they are up to the task", "Recycle nurses every time", "Recall certain stories that we have already forgotten", "Defining the acts of the nurse", “... also having training... that we are all considered as the service providers...”, “... encourage and evaluate it when it has all at its disposal". Zewdu found that the hospital's governing body should circulate and oversee the implementation of the nursing process in the hospital, the practitioner should train periodically, and information should be disseminated about the nursing process [4].

Zaragoza mentions among the factors that facilitated the implementation of the nursing process, the nursing process education program, with particular attention to increasing knowledge, changing attitudes and nurse skill development [3]. 
In Iran [6], the personal level nurses need to be sensitized and at the management level, supervision is needed to implement the nursing process.

According to Mulugeta most respondents agreed that knowledge is a determining factor that could influence the implementation of the nursing process [14].

\section{e) Motivation}

Motivation in relation to our study becomes the fifth leading factor in the implementation of the nursing process. Respondents say, "First of all, we are paid at first, we are really discouraged", “... it is also a motivation when we give promotion to someone it is a way to encourage it ...", "Nurse Invoicing", "Nurse ... mostly motivated, however marginalized, somewhat discriminated, works a little too much and receives little, so a little money ... it will not work well ...”. Mulugeta found that the respondents reported a mediocre payment, and they said they were working for food and not for the profession [14].

\section{f) Availability of work equipment}

It was reported as motivating the nurse to the implementation of the nursing process. The work is facilitated and motivating when all the conditions are met. "I do not have a syringe, I do not have a thermometer, fucked blood pressure monitor", "no tool", "not a bed that carries a sheet", "lack of care equipment".

Afoi found that the solutions proposed by the nurses were that basic nursing care facilities for patients had to be available [5].

In DR Congo, the General Reference Hospitals and other HGR structures offer high quality care because of the inadequacy of specific medicines and inputs and adequate working materials [15].

\section{Conclusions}

We have found that the factors that can favor the implementation of the nursing process cited by the nurses of the public hospitals of Lubumbashi are:

- The improvement of the esteem, the image of the nurse and the social climate,

- The setting up of the nursing file,

- The availability of nursing staff (actual),

- Updating knowledge on the nursing process,

- The motivation of the nurses (salary, promotion, bonus, etc.,

- Availability of work equipment.

Our suggestions are the followings:

To the Minister of Health:

Review of nurses' salaries;

Supervision of nurses' work in HGR;

Provide hospitals with resources to facilitate the implementation of the nursing process (equipment, nursing workforce, nurse's file, etc.);

Encourage ongoing training of provincial presidents of ANIC (nurses' order) as well as nursing directors on the nursing process, which in turn will make res- 
titution;

Transform nurse education (training) into university curricula;

Review and review, where possible, the nursing education program at all levels.

\section{To the nursing council}

Raising awareness and training of nurses on the value of nursing care and enhancing their skills;

Implementation of the nursing file;

Training of nurses on the nursing process.

\section{To Hospitals board of management}

Recognize the nursing process to other health professionals present in the hospital;

Motivate nurses through promotions; Provide resources within nursing units to facilitate the implementation of the nursing process: review the number of nurses according to the number of patients, availability of sufficient equipment in the nursing units in quantities and quality and more.

Introduce retraining of nurses in their field.

\section{To nursing education institutions}

Integrate the nursing process into the training program as already required in the program of secondary school nurses in the Democratic Republic of Congo, respecting the five competences (Establish professional communication, make decisions on health problems, carry out nursing interventions, manage resources, engage in professional development). Strictly follow his theoretical training in schools and his practical training in hospitals.

To other health workers

Recognize the nursing process and consider nurses as collaborators with whom they must share in order to jointly resolve the problems of the patients at their disposal, taking into account their different skills.

\section{To Nursing Directors and Heads of Care Units}

To work in collaboration with the nursing council to strengthen nurses' knowledge of the nursing process, to assign nurses the responsibilities of patients and not tasks for individualized, comprehensive and quality care;

Developing requirements for the operation of the units of care, which involves collaboration with the hospital manager;

Regularly evaluate nurses' work to identify training needs and improve quality of care.

To the nurses

Let the nurses stand up to fight, for no one can lead the battle in their place.

Let them become aware and acknowledge their profession to make it known to others; that they commit themselves to change, follow the nursing education course and put it into practice to enhance the profession and improve the quality of care;

That they are not limited to the role of prescription, but that they also carry out acts in relation to their own role, which requires the implementation of the 
nursing process;

That they do the research in nursing to be up to date;

That they take into account the patients' requests for adequate answers;

That they consider other health professionals as collaborators with whom they must share their different skills to solve the needs of patients;

That they follow the university studies of the bachelor, master and doctorate level to facilitate the understanding in this multidisciplinary because the other health professionals with whom they must share are either licensed or masters or professors in their field;

Finally, we recall that our study is the first to deal with this issue in Lubumbashi, and we are convinced that it contains deficiencies. We suggest that other researchers deepen it across the province as well as across the country.

\section{Ethical Clearance}

This work has been approved by the Ethics Committee of the University of Lubumbashi.

\section{References}

[1] EU (2016) Theories of Care and History of the Profession ide.

[2] Aiyedun, Chukwu and Musa, R.H. (2014) Evaluation of the Challenges of Nursing Process Practice at the University of Abuja Teaching Hospital, Nigeria. Journal of Medical and Health Sciences, 4, 93-100.

[3] Salcedo, A.Z. (2004) Implementing the Nursing Process in a Teaching Hospital Ward: An Action Research Study Amparo Zaragoza Salcedo MSc, RN Submitted in Partial Fulfilment of the Requirements for the Degree of $\mathrm{PhD}$.

[4] Shewangizaw, Z. and Mersha, A. (2015) Determinants towards Implementation of Nursing Process. American Journal of Nursing Science, 4, 45-49. https://doi.org/10.11648/j.ajns.20150403.11

[5] Emmanuel, A., Achema, G., Bb, A. and Kr, M. (2014) Self Medication Practice among Pregnant Women Attending Antenatal Clinic in Selected Hospitals in Jos, Nigeria Study Design. 46-51.

[6] Rahmani, M., Davarpanah, M., Naseri, M. and Hamedpour, H. (2017) The Effect of Nursing Process Implementation Using “Accessible Care Cards” Method on Satisfaction Rate of Nurses, Patients and Parents of Inpatient Children of Care Manner. 121-130.

[7] Siemuri, K.E., Oladayo, O.F. and Ugochukwu, N.C. (2014) Factors Influencing the Utilization of the Nursing Process in Ogun State, Nigeria. International Journal of General Medicine and Pharmacy (IJGMP), 3, 57-64.

[8] Hagos, F., Alemseged, F., Balcha, F., Berhe, S. and Aregay, A. (2014) Application of Nursing Process and Its Affecting Factors among Nurses Working in Mekelle Zone Hospitals, Northern Ethiopia. Nursing Research and Practice, 2014, 1-8. https://doi.org/10.1155/2014/675212

[9] Aslakson, R.A., et al. (2012) Nurse-Perceived Barriers to Effective Communication Regarding Prognosis and Optimal End-of-Life Care for Surgical ICU Patients: A Qualitative Exploration. Journal of Palliative Medicine, 15, 910-915.

https://doi.org/10.1089/jpm.2011.0481 
[10] Mahmoud, M.H.M.M.H. and Bayoumy, H.H.M.H. (2014) Barriers and Facilitators for Execution of Nursing Process from Nurses' Perspective. International Journal of Advanced Research, 2, 300-315.

[11] Afolayan, J.A., Donald, B., Baldwin, D.M., Onasoga, O. and Babafemi, A. (2013) Evaluation of the Utilization of Nursing Process and Patient Outcome in Psychiatric Nursing : Case Study of Psychiatric Hospital Rumuigbo, Port Harcourt. Advances in Applied Science Research, 4, 34-43.

[12] Ahonzi, B. (2013) Implementation of the Nursing File in the Health Services in Cote d'Ivoire: Case of the Pediatric Department of the Chu de Trechville.

[13] Santana, J. (2014) Quality of Nursing Care and Satisfaction of Patients Attended at a Teaching Hospital. Revista Peruana de Medicina Experimental y Salud Pública, 31, 461-466.

[14] (2011) College of Health Science Department of Nursing and Midwifery Postgraduate Program College of Health Science Department of Nursing and Midwifery a Thesis Submitted to the School of Graduate Studies of Addis Ababa University in Partial Fulfillment of the $r$.

[15] DRC-PNDS (2010) Ministry of Public Health. National Health Development Plan 2011-2015.

Submit or recommend next manuscript to OALib Journal and we will provide best service for you:

- Publication frequency: Monthly

- 9 subject areas of science, technology and medicine

- Fair and rigorous peer-review system

- Fast publication process

- Article promotion in various social networking sites (LinkedIn, Facebook, Twitter, etc.)

- Maximum dissemination of your research work

Submit Your Paper Online: Click Here to Submit

Or Contact service@oalib.com 